\title{
Daily physical activity and macronutrient distribution of low-calorie diets jointly affect body fat reduction in obese women
}

\author{
Constanza Matilde López-Fontana, Almudena Sánchez-Villegas, \\ Miguel Angel Martínez-Gonzalez, and José Alfredo Martinez
}

\begin{abstract}
Inadequate dietary patterns and sedentary lifestyles are believed to be important factors in predisposing people to obesity. This study analyzed the potential interaction between habitual physical activity and the carbohydrate (CHO)-fat distribution in 2 hypocaloric diets and the impact of such interplay on body composition changes. Forty healthy obese women, 20-50 years old, were randomly assigned to a high- or low-CHO energy-restricted diet, which was low or high in fat, respectively, during 10 weeks. Baseline and final measurements were performed to assess dietary habits, resting metabolic rate, and body composition changes. Physical activity was measured with a triaxial accelerometer and with a questionnaire. There were no significant differences in anthropometric and metabolic variables between both dietary groups at baseline. However, there was a positive correlation between total free-living physical activity and arm muscle preservation after 10 weeks $(r=0.371 ; p=0.024)$. Interestingly, an interaction between macronutrient (CHO-fat distribution) intake and physical activity was found, since less-active subjects with a high-CHO-low-fat diet showed a greater fat loss than those more active with a lower-CHO-high-fat diet, whereas more-active subjects with a high-CHO-low-fat diet showed a smaller fat loss than those receiving a low-CHO-high-fat diet. Physical activity and the macronutrient content of energyrestricted diets, when designed to promote body fat mass reduction, should be considered together to better predict the outcome.
\end{abstract}

Key words: physical activity, carbohydrate intake, fat intake, macronutrient content, fat mass, hypocaloric diets, sedentarism.

Résumé : Une mauvaise alimentation et un mode de vie sédentaire constituent des facteurs qui prédisposent à l'obésité. Cette étude se propose d'analyser l'interaction potentielle des habitudes en matière d'activité physique et de la proportion des sucres et des gras dans 2 diètes hypocaloriques et d'en vérifier les effets sur la variation de composition corporelle. On répartit aléatoirement 40 femmes obèses, en bonne santé et âgées de 20 à 50 ans dans 2 groupes de régime hypocalorique, à forte ou faible teneur en sucre; la teneur en gras est respectivement faible ou forte. La durée du régime est de 10 semaines. Au début et à la fin de ce programme, on évalue les variables suivantes : les habitudes alimentaires, le métabolisme de repos (RMR) et la composition corporelle. On mesure l'activité physique au moyen d'un accéléromètre triaxial et d'un questionnaire. Au début du programme, on n'observe chez les deux groupes suivant le régime aucune différence significative entre les valeurs des variables anthropométriques et métaboliques. Cependant, on observe à la fin du programme une corrélation positive entre l'activité physique pratiquée librement et la préservation de la masse musculaire du bras $(r=0,371 ; p=0,024)$.Digne de mention, on observe une interaction entre l'apport de macronutriments (sucres/gras) et l'activité physique; les sujets les moins actifs dont le régime est fort en sucre et faible en gras perdent plus de masse adipeuse que les sujets plus actifs mais dont le régime est faible en sucre et fort en gras; en retour, les sujets les plus actifs au régime fort en sucre et faible en gras perdent moins de masse adipeuse que les sujets au régime faible en sucre et fort en gras. Dans l'élaboration de régimes hypocaloriques pour diminuer la masse adipeuse, on devrait prendre en compte l'activité physique et la proportion de sucre et des gras dans l'apport alimentaire.

Mots-clés : activité physique, apport en sucre, apport de gras, teneur en macronutriments, masse adipeuse, régimes hypocaloriques, sédentarisme.

[Traduit par la Rédaction]

Received 13 July 2008. Accepted 30 January 2009. Published on the NRC Research Press Web site at apnm.nrc.ca on .

C.M. López-Fontana. Dpto. Fisiología y Nutrición, Universidad de Navarra, Irunlarrea, 1 (31008), Pamplona, Spain; Laboratorio de Enfermedades Metabólicas y cáncer, Universidad Juan Agustín Maza, Acceso Este 2245, San José, Guaymallén (5519), Mendoza, Argentina.

A. Sánchez-Villegas. Dpto. Medicina Preventiva y Salud Pública, Universidad de Navarra, Irunlarrea, 1 (31008), Pamplona, Spain; Dpto. Ciencias Clínicas, Universidad de Las Palmas de Gran Canaria, C/Juan de Quesada, $n^{\circ}$ 30- Las Palmas de Gran Canaria (35001), Spain. M.A. Martínez-Gonzalez. Dpto. Medicina Preventiva y Salud Pública, Universidad de Navarra, Irunlarrea, 1 (31008), Pamplona, Spain. J.A. Martinez. ${ }^{1}$ Dpto. Fisiología y Nutrición, Universidad de Navarra, Irunlarrea, 1 (31008), Pamplona, Spain.

${ }^{1}$ Corresponding author (e-mail: jalfmtz@unav.es). 


\section{Introduction}

The prevalence of obesity is currently reaching epidemic proportions in developed and low-income countries (Ford et al. 2005; Janiszewski and Ross 2007). Indeed, some environmental-related obesity predictors and determinants of the interactions between dietary habits and sedentary lifestyles involved in weight gain are being elucidated (Bes-Rastrollo et al. 2006). Dietary macronutrient composition in energyrestricted diets clearly has an important influence on body weight loss by affecting appetite, thermogenesis, or other metabolic processes (Abete et al. 2006). Also, it has been reported that macronutrient oxidation and total energy expenditure in obese individuals might be modified in response to changes in diet composition (Blaak et al. 2007) and that body composition is influenced by physical activity (Ekelund et al. 2007).

Changes in body fat stores are viewed as an imbalance in fat intake and oxidation, whereas oxidative hierarchy operates in inverse direction to the size of available stores for each macronutrient, facilitating fat accumulation (Blundell et al. 2002). Thus, it is assumed that dietary carbohydrates (CHO) promote their own oxidation, whereas high-fat meals do not acutely increase fat oxidation (Prentice 1998). There are several factors that support a link between dietary fat and obesity development: energy from fat is less satiating than energy from $\mathrm{CHO}$; a high-fat/CHO ratio in the diet promotes passive overconsumption; $\mathrm{CHO}$ is more thermogenic than fat; and postprandial fuel selection favors the oxidation of dietary $\mathrm{CHO}$, whereas excess dietary fats are preferentially stored as triacylglycerol in adipose tissue (Astrup et al. 2004). However, a dietary intervention randomized controlled trial that compared the effectiveness and safety of 3 weight-loss diets concluded that Mediterranean and lowCHO diets may be effective alternatives to low-fat diets, because the low-CHO diets showed more favorable effects on lipids, whereas the Mediterranean diet pattern did so on glycemic control (Shai et al. 2008).

A sedentary lifestyle with a low level of energy expended on physical activities is another causal factor for weight gain (Schrauwen and Westerterp 2000; Schrauwen 2007) that may interact with dietary energy content (Karnehed et al. 2006). Furthermore, individuals with a sedentary lifestyle and low physical fitness may, as a result, have a low muscle fat oxidation capacity, which might promote fat storage after the consumption of a high-fat diet (Smith et al. 2000).

The objective of this study was to analyze the influence of 2 hypocaloric diets with different macronutrient composition (high-CHO-low-fat diet compared with low-CHO-highfat diet) and habitual physical activity on weight changes and fat loss in obese women. Our hypothesis was that macronutrient oxidation and body composition changes might be simultaneously and differentially affected by both diet and habitual physical activity in energy-restricted conditions.

\section{Materials and methods}

\section{Study population}

A sample of 40 obese women was recruited for this interventional prospective trial, which was randomized by using a computerized random number generator at baseline. The number of volunteers was based on sample size calculations using data from published reports (Abete et al. 2008). The subjects were healthy, as determined by a trained physician with previous expertise in enrolling subjects for nutritional trials. Except for excessive body weight, subjects had no known endocrine or metabolic disease, and were not taking drugs known to affect appetite or energy expenditure. Volunteers were selected according to the following inclusion criteria: female, aged 20-50 years old, with a body mass index (BMI) equal to or higher than $29.5 \mathrm{~kg} \cdot \mathrm{m}^{-2}$ at study day 1 (baseline) and self-reported regular menses. Participants with high blood pressure, diabetes mellitus, or drugtreated hyperlipidemia, or who had participated in a clinical trial during the last 3 months, were excluded from the study. Prospective volunteers who followed unconventional dietary habits, such as vegans, etc., were not invited to participate in the study. There were no dropouts. This was attributed to the characteristics of the study follow-up and the fact that all the obese women actually lost weight.

The subjects participated in the study after giving a written consent, which was approved by the Local Ethics Committee at the Navarra University Clinic.

\section{Design}

The study included individual nutritional interviews at the beginning of the study, at study day 1, and at study day 70 . Moreover, regular nutritional assessments were carried out throughout the intervention period. Finally, measurements of body composition and resting metabolic rate (RMR) were performed during study day 1 and study day 70, and subjective and objective measurements of habitual physical activity were carried out in the fifth week of the dietary intervention (from day 32 to day 36).

\section{Nutritional interview}

During the screening, the volunteers attended a nutritional interview to complete a detailed dietary history of the previous year. Also, information and criteria for a $72 \mathrm{~h}$ weighed food record were given. This protocol consisted of weighing all foods consumed for 3 days on an electronic scale (ODAG, Madrid, Spain), which was lent to the participants during the study. Subjects received instructions from the dietitian on how to keep a food record and were asked not to change their habitual food intake during two 3-day recording periods (prior to study day 1). Food records were analyzed with software based on Spanish food tables (Medisystem, SANOCARE, Alcobendas, Spain) for total energy and macronutrient content.

\section{Nutritional intervention}

At the end of study day 1, volunteers were assigned to consume 1 of 2 experimental hypocaloric regimens with different macronutrient content, a low-CHO-high-fat $(n=19)$ or a high-CHO-low-fat $(n=21)$ diet, for 10 weeks.

The energy content of the diets was individually prescribed for each subject according to the following formula: RMR $\times$ physical activity level $(\mathrm{PAL})$ factor $-600 \mathrm{kcal}$. The personalized energy intake was achieved by the individualized RMR measurement and the assigned PAL, depending on the declared occupational and discretionary physical activities (World Health Organization 1998). The composition of the high-CHO-low-fat diet was designed to provide $55 \%-$ 
$60 \%$ energy intake from $\mathrm{CHO}, 15 \%-20 \%$ energy intake from protein, and 25\%-30\% energy intake from fat. The composition of the low-CHO-moderately high-fat diet was designed to provide $40 \%-45 \%$ energy intake from $\mathrm{CHO}$, $15 \%-20 \%$ energy intake from protein, and 35\%-40\% energy intake from fat. Both dietary groups were instructed to follow a similar and regular pattern of meals per week according to local habits. All food groups (grains and starches, fruits, vegetables, meat, dairy products, oil, etc.) were included in the dietary patterns. Once the experimental diet was assigned to each volunteer and the energy content of the diet calculated, the timing and the food distribution was planned according to the food preferences of each participant, taking strictly into consideration the composition of the experimental diet. Additionally, a calibration of each diet was made through standard software to confirm that the requirements of the diets were met. Each volunteer received a plan detailing the food distribution, quantities of each food, weekly meal menu, quantity of oil permitted per day, recipes and cooking techniques, and specific suggestions, following a similar system as described elsewhere (Abete et al. 2008). Subjects were supervised weekly by the same dietitian to optimally adjust their compliance with the diet, and all volunteers kept records of daily intakes throughout the study.

\section{Study day 1 and study day 70: anthropometric and substrate oxidation measurements}

At study day 1 and study day 70, subjects underwent anthropometric and RMR measurements. Anthropometric measurements included height, weight, waist and hip circumference, arm circumference, and skinfold thickness, which were measured according to standardized criteria (Gibson 2005). The sum of skinfold thickness was calculated by adding the triceps and biceps, the subscapular skinfold, and the suprailiac skinfold thickness. Skinfold measurements were taken 3 times with a caliper (Holtain Ltd., Crymech, UK). The midarm circumference and the triceps skinfold thickness were used in the calculation of the arm muscle area and arm fat area.

Furthermore, body composition (fat and lean mass) was measured by bioelectrical impedance analysis, following the manufacturer's instructions (MultiScan 5000, Bodystat, Copenhagen Denmark). All anthropometric measurements were performed at 0800 hours, in a fasting state, following standardized procedures (Gibson 2005).

Volunteers fasted overnight and arrived by car or bus at the metabolic room. After voiding, they rested supine for 30 min, after which the RMR was measured during a $25 \mathrm{~min}$ interval. Respiratory exchange determinations were performed using a computerized open circuit indirect calorimeter with a rigid transparent ventilated hood (Deltatrac, Datex-Engstrom, Finland). CHO and fat oxidation were calculated as described elsewhere (Ferrannini 1988).

The participants were informed about the correct collection of every urinary output during the night and the first output in the morning. Urinary nitrogen excretion was measured by the Kjeldahl method. Weir's equations were used to calculate RMR based on oxygen intake, carbon dioxide production, and urinary nitrogen excretion (Ferrannini 1988).

\section{Physical activity estimation}

A physical activity validated questionnaire (MartínezGonzalez et al. 2005) was administered at the beginning of the study to subjectively personalize the PAL factor, which was based on World Health Organization criteria that combines occupational and discretionary physical activity. The PAL factor ranged from 1.2 to 1.4 , with 1.3 being the modal value because of the sedentary or light physical activity lifestyles of all volunteers. Participants had occupations that did not demand much physical effort and that did not require walking long distances; they generally used motor vehicles for transportation, did not exercise or practice sports regularly, and spent most of the time sitting or standing with little body displacement (e.g., talking, reading, using computers, listening, watching television, etc.).

The number of metabolic equivalents (METs) corresponding to each activity was calculated using the Compendium of Physical Activities (Ainsworth et al. 2000). MET values assess the ratio of energy expended during a physical activity to the metabolic rate (energy expenditure) of sitting quietly. Total physical activity (METs $\left(\mathrm{h} \cdot\right.$ week $\left.^{-1}\right)$ ) was calculated by adding recreational activity to occupational activities.

A sedentary index was calculated using the activityinactivity lifestyle indicators included in the questionnaire for a typical workday and for a typical weekend day. It was defined based on the total number of hours spent sitting per week (Martinez-Gonzalez et al. 1999).

Participants wore an RT3 triaxial accelerometer (Tritrac, Research Tracker, Stayhealthy, Calif.) for 3 days in a typical week and 2 days during the weekend on the fifth week of the dietary intervention from day 32 to 36 . The vector values were converted into energy expenditure $\left(\mathrm{kcal} \cdot \mathrm{day}^{-1}\right)$ to calculate the free-living activity energy expenditure.

\section{Statistical analyses}

Differences in anthropometrical, metabolic, and physical activity-related variables according to the type of diet (highCHO-low-fat vs. low-CHO-high-fat) were compared using Student's $t$ tests if the quantitative variable followed a normal distribution. If the distribution of quantitative variables was not normal, a nonparametric test (Mann-Whitney $U$ test) was used. The association between changes in anthropometrical and metabolic characteristics of the participants throughout the experimental time (final-baseline value) and the reported and measured physical activity estimates were analyzed using parametric tests (Pearson coefficient). Means and coefficients were adjusted for age to avoid potential confounding. Finally, the interaction between the type of diet consumed (high- vs. low-CHO) and physical activity (measured as total free-living physical activity, occupational activity, or the sedentary index on the basis of the questionnaire) was assessed through a 2-way factorial analysis of variance (ANOVA) (diet $\times$ physical activity), which is a suitable and robust model to analyze potential statistical interactions between 2 variables. Subjects were assigned to 1 of 2 groups, depending on the reported habitual physical activity using the median cut-off criterion (above or below the 50th percentile) to statistically ensure similar numerical distribution in both groups (half that were more active vs. half less active). $P$ values $<0.05$ were considered to be statistically significant for all analyses. The SPSS software package (2005) for Windows, ver- 
Table 1. Baseline characteristics of obese women assigned to the 2 prescribed experimental diets: low-carbohydrate-high-fat vs. high-carbohydrate-low-fat.*

\begin{tabular}{|c|c|c|}
\hline & $\begin{array}{l}\text { Low-CHO-high-fat } \\
(n=19)\end{array}$ & $\begin{array}{l}\text { High-CHO-low-fat } \\
(n=21)\end{array}$ \\
\hline Variable & Mean \pm SD & Mean \pm SD \\
\hline Age (y) & $34.2 \pm 6.2$ & $34.5 \pm 7.9$ \\
\hline Weight (kg) & $94.5 \pm 14.0$ & $94.9 \pm 17.8$ \\
\hline Body mass index $\left(\mathrm{kg} \cdot \mathrm{m}^{-2}\right)$ & $36.9 \pm 5.2$ & $37.4 \pm 6.9$ \\
\hline Waist circumference $(\mathrm{cm})$ & $99.8 \pm 13.5$ & $101.1 \pm 14.3$ \\
\hline Hip circumference $(\mathrm{cm})$ & $121.0 \pm 13.1$ & $122.4 \pm 14.6$ \\
\hline Waist/hip ratio & $0.82 \pm 0.04$ & $0.83 \pm 0.04$ \\
\hline Triceps skinfold thickness (mm) & $36.4 \pm 3.1$ & $36.9 \pm 3.9$ \\
\hline Skinfold thickness sum (mm) & $129.6 \pm 14.6$ & $132.7 \pm 22.6$ \\
\hline Muscle arm area $\left(\mathrm{cm}^{2}\right)$ & $54.4 \pm 10.1$ & $53.0 \pm 11.4$ \\
\hline Arm fat area $\left(\mathrm{cm}^{2}\right)$ & $57.9 \pm 7.4$ & $58.3 \pm 10.4$ \\
\hline Free fat mass $(\mathrm{kg})$ & $49.9 \pm 3.9$ & $50.3 \pm 5.6$ \\
\hline Body fat percentage $(\%)^{\dagger}$ & $46.5 \pm 4.9$ & $46.3 \pm 5.1$ \\
\hline CHO oxidation $\left(\mathrm{g} \cdot 24 \mathrm{~h}^{-1}\right)$ & $101.6 \pm 39.4$ & $111.9 \pm 47.8$ \\
\hline Fat oxidation $\left(\mathrm{g} \cdot 24 \mathrm{~h}^{-1}\right)$ & $118.1 \pm 29.9$ & $105.5 \pm 35.2$ \\
\hline Protein oxidation $\left(\mathrm{g} \cdot 24 \mathrm{~h}^{-1}\right)$ & $53.1 \pm 27.5$ & $61.3 \pm 23.2$ \\
\hline Resting metabolic rate $\left(\mathrm{kcal} \cdot 24 \mathrm{~h}^{-1}\right)$ & $1696 \pm 134$ & $1698 \pm 181$ \\
\hline Sedentary index $\left(\mathrm{h} \cdot \mathrm{wk}^{-1}\right)$ & $40.3 \pm 19.9$ & $39.3 \pm 13.9$ \\
\hline Recreational activity $\left(\operatorname{METs}\left(\mathrm{h} \cdot \mathrm{wk}^{-1}\right)\right)^{*}$ & $7.6 \pm 11.2$ & $6.2 \pm 7.5$ \\
\hline Activity at work $\left(\text { METs }\left(h \cdot w^{-1}\right)\right)^{*}$ & $160.5 \pm 82.1$ & $114.9 \pm 64.9$ \\
\hline Total free-living activity $\left(\text { METs }\left(h \cdot w^{-1}\right)\right)^{*}$ & $168.1 \pm 87.4$ & $121.1 \pm 65.9$ \\
\hline Triaxial accelerometer $\left(\mathrm{kcal} \cdot \mathrm{d}^{-1}\right)$ & $1002.0 \pm 389.3$ & $910.3 \pm 324.2$ \\
\hline
\end{tabular}

sion 13.0 (SPSS Inc., Chicago Ill.), was used for statistical analyses.

\section{Results}

The average BMI and body fat percentage in the enrolled sample were $37.1 \pm 6.1 \mathrm{~kg} \cdot \mathrm{m}^{-2}$ and $43.3 \pm 5.3 \%$, respectively $(n=40)$ at baseline. The group of volunteers had a BMI $>29.8 \mathrm{~kg} \cdot \mathrm{m}^{-2}$ and a waist/hip ratio $<0.90$. No statistical differences were found in baseline anthropometrics, RMR, macronutrient oxidation, or physical activity estimations between the obese women consuming either the high-CHOlow-fat diet or the low-CHO-high-fat diet (Table 1).

Defined macronutrient goals for $\mathrm{CHO}$ (43.2\% vs. $57.7 \%$ energy intake) and fat intake (39.6\% vs. $26.7 \%$ energy intake) were met according to the design (Table 2). Furthermore, protein, fatty acid profile, simple to complex $\mathrm{CHO}$ ratio, and fiber intake were consistent with the 2 designed and prescribed interventions (Table 2).

Anthropometrical changes (weight, skinfolds, circumferences, etc.) were similar in both dietary groups (Table 3), which showed comparable reductions in BMI $\left(3.0 \mathrm{~kg} \cdot \mathrm{m}^{-2}\right.$ and $2.9 \mathrm{~kg} \cdot \mathrm{m}^{-2}$, respectively); this represented a loss of approximately $6 \mathrm{~kg}$ of fat mass. Calculated RMR was comparable at baseline in the 2 groups and similarly decreased $\left(-196 \mathrm{kcal} \cdot 24 \mathrm{~h}^{-1}\right.$ and $-206 \mathrm{kcal} \cdot 24 \mathrm{~h}^{-1}$, respectively) with weight loss. The macronutrient oxidation values at study day 1 were within the expected values for an obese population (Table 1) and no differences were found as a conse- quence of the slimming process. In both experimental groups, the contribution to energy expenditure from fat oxidation increased by about $4 \%-5 \%$.

Physical activity was estimated from a triaxial accelerometer and 2 indices (sedentary index and total free-living activity), both obtained through a validated Spanish questionnaire. We compared the different estimations of physical activity to test their validity. As a result, the Spearman correlation between the sedentary index and total freeliving activity was $-0.453(p=0.034)$, whereas the correlation between the sedentary index and the accelerometer values was $-0.415(p=0.01)$.

A direct correlation between total free-living activity $\left(\operatorname{METs}\left(\mathrm{h} \cdot\right.\right.$ week $\left.^{-1}\right)$ ) and the arm muscle area preservation (final-baseline values) was found ( $r=0.371 ; p=0.024)$, indicating that a higher total free-living activity was associated with a smaller reduction in the arm muscle area (Fig. 1). Statistically significant results were also found when the group receiving the high-CHO-low-fat diet was analyzed separately $(r=0.50 ; p=0.031)$. Furthermore, an inverse association between the sedentary index and the change between the final and baseline arm muscle area was found $(r=-0.367 ; p=0.021)$. The association between fatfree mass measured by bioelectrical impedance and physical activity followed the same expected trends but did not achieve statistical significance $(p>0.05)$.

Interestingly, both the activity at work (METs $\left(\mathrm{h} \cdot\right.$ week $\left.\left.^{-1}\right)\right)$ measurements (Fig. 2A) and the sedentary index (h.week ${ }^{-1}$ ) analysis (Fig. 2B) revealed that subjects who were less ac- 
Table 2. Macronutrient intake as reported on the 72-h weighted food records from obese women in the 2 prescribed experimental dietary groups: low-carbohydrate-high-fat vs. high-carbohydratelow-fat after 10 weeks of weight loss.

\begin{tabular}{lcc}
\hline & $\begin{array}{l}\text { Low-CHO- } \\
\text { high-fat } \\
(n=19)\end{array}$ & $\begin{array}{c}\text { High-CHO- } \\
\text { low-fat } \\
(n=21)\end{array}$ \\
\cline { 2 - 3 } Mean+SD & Mean+SD \\
Macronutrient intake & $1451 \pm 236$ & $1439 \pm 319$ \\
\hline Energy intake $\left(\mathrm{kcal} \cdot 24 \mathrm{~h}^{-1}\right)$ & $64.5 \pm 14.9$ & $66.6 \pm 16.4$ \\
Protein $\left(\mathrm{g} \cdot 24 \mathrm{~h}^{-1}\right)$ & $17.7 \pm 2.5$ & $18.6 \pm 2.3$ \\
Protein $\left(\%\right.$ energy intake) $^{-1}$ & $64.3 \pm 16.4$ & $43.4 \pm 14.7$ \\
Lipid $\left(\mathrm{g} \cdot 24 \mathrm{~h}^{-1}\right)$ & $39.6 \pm 5.4$ & $26.7 \pm 4.1 *$ \\
Lipid $(\%$ energy intake) & $13.7 \pm 4.7$ & $10.4 \pm 4.4$ \\
Saturated fat $\left(\mathrm{g} \cdot 24 \mathrm{~h}^{-1}\right)$ & $37.9 \pm 11.9$ & $25.1 \pm 7.7$ \\
Monounsaturated fat $\left(\mathrm{g} \cdot 24 \mathrm{~h}^{-1}\right)$ & $7.7 \pm 1.9$ & $5.7 \pm 2.4$ \\
Polyunsaturated fat $\left(\mathrm{g} \cdot 24 \mathrm{~h}^{-1}\right)$ & $162.8 \pm 27.9$ & $206.2 \pm 43.4$ \\
CHO $\left(\mathrm{g} \cdot 24 \mathrm{~h}^{-1}\right)$ & $43.2 \pm 6.1$ & $57.7 \pm 5.2$ \\
CHO $(\%$ energy intake) & $81.5 \pm 21.2$ & $90.7 \pm 23.5$ \\
Simple CHO $\left(\mathrm{g} \cdot 24 \mathrm{~h}^{-1}\right)$ & $81.3 \pm 17.5$ & $115.3 \pm 23.8$ \\
Complex CHO $\left(\mathrm{g} \cdot 24 \mathrm{~h}^{-1}\right)$ & $1.04 \pm 0.37$ & $0.8 \pm 0.19$ \\
Simple/complex carbohydrate ra- & & \\
$\quad$ tio & $19.2 \pm 6.5$ & $28.1 \pm 16.1$ \\
Fiber $\left(\mathrm{g} \cdot 24 \mathrm{~h} \mathrm{~h}^{-1}\right)$ &
\end{tabular}

Note: All comparisons not statistically different unless stated ${ }^{\dagger}$ or $*$ $\mathrm{CHO}$, carbohydrate.

${ }^{*} p<0.001$ lower in the low-CHO-high-fat diet.

${ }^{\dagger} p<0.001$ greater in the high-CHO-low-fat diet.

Table 3. Changes in anthropometrical and metabolic characteristics (final-baseline values) induced by the 2 prescribed experimental diets in obese women: low-carbohydrate-high-fat vs. highCHO-low-fat after 10 weeks of weight loss intervention.

\begin{tabular}{lll}
\hline & $\begin{array}{l}\text { Low-CHO- } \\
\text { high-fat } \\
(n=19)\end{array}$ & $\begin{array}{l}\text { High-CHO- } \\
\text { low-fat } \\
(n=21)\end{array}$ \\
\cline { 2 - 3 } Vean \pm SD & Mean \pm SD \\
\hline Weight $(\mathrm{kg})$ & $-7.82 \pm 2.84$ & $-7.34 \pm 2.68$ \\
Body mass index $\left(\mathrm{kg} \cdot \mathrm{m}^{-2}\right)$ & $-3.03 \pm 1.07$ & $-2.90 \pm 1.07$ \\
Hip circumference $(\mathrm{cm})$ & $-6.38 \pm 3.79$ & $-5.78 \pm 4.36$ \\
Waist/hip ratio & $-0.01 \pm 0.05$ & $-0.01 \pm 0.26$ \\
Triceps skinfold thickness $(\mathrm{mm})$ & $-2.94 \pm 2.69$ & $-2.66 \pm 2.38$ \\
Arm muscle area $\left(\mathrm{cm}^{2}\right)$ & $-4.69 \pm 6.02$ & $-4.74 \pm 3.76$ \\
Arm fat area $\left(\mathrm{cm}^{2}\right)$ & $-7.22 \pm 3.30$ & $-6.82 \pm 3.91$ \\
Fat-free mass $(\mathrm{kg})$ & $-1.59 \pm 1.22$ & $-1.27 \pm 1.41$ \\
Fat mass $(\mathrm{kg})$ & $-6.23 \pm 2.66$ & $-6.07 \pm 2.74$ \\
Resting metabolic rate & $-196.3 \pm 165.0$ & $-206.5 \pm 158.5$ \\
$\quad\left(\mathrm{kcal} \cdot 24 \mathrm{~h}^{-1}\right)$ & & \\
\hline
\end{tabular}

Note: No comparisons were statistically significant. $\mathrm{CHO}$, carbohydrate.

tive and had a higher $\mathrm{CHO}$ intake showed a greater decrease in fat mass ( $p$ for interaction < 0.05). In contrast, those obese women who were more physically active (more activity at work or lower sedentary index) lost less fat mass when assigned to the high-CHO-low-fat diet (Fig. 2A and 2B).

\section{Discussion}

A high $\mathrm{CHO}$ intake with a concomitant reduction in dietary fat has been recommended to reduce total energy intake
Fig. 1. Correlation between age-adjusted total free-living activity calculated from the physical activity questionnaire (expressed in metabolic equivalents (METs) $\left(\mathrm{h} \cdot\right.$ week $\left.^{-1}\right)$ ) and the change in the arm muscle area (final-baseline values) after 10 weeks of weight loss induced by the 2 prescribed energy-restricted approaches: lowcarbohydrate-high-fat vs. high-carbohydrate-low-fat diets $(n=36)$.

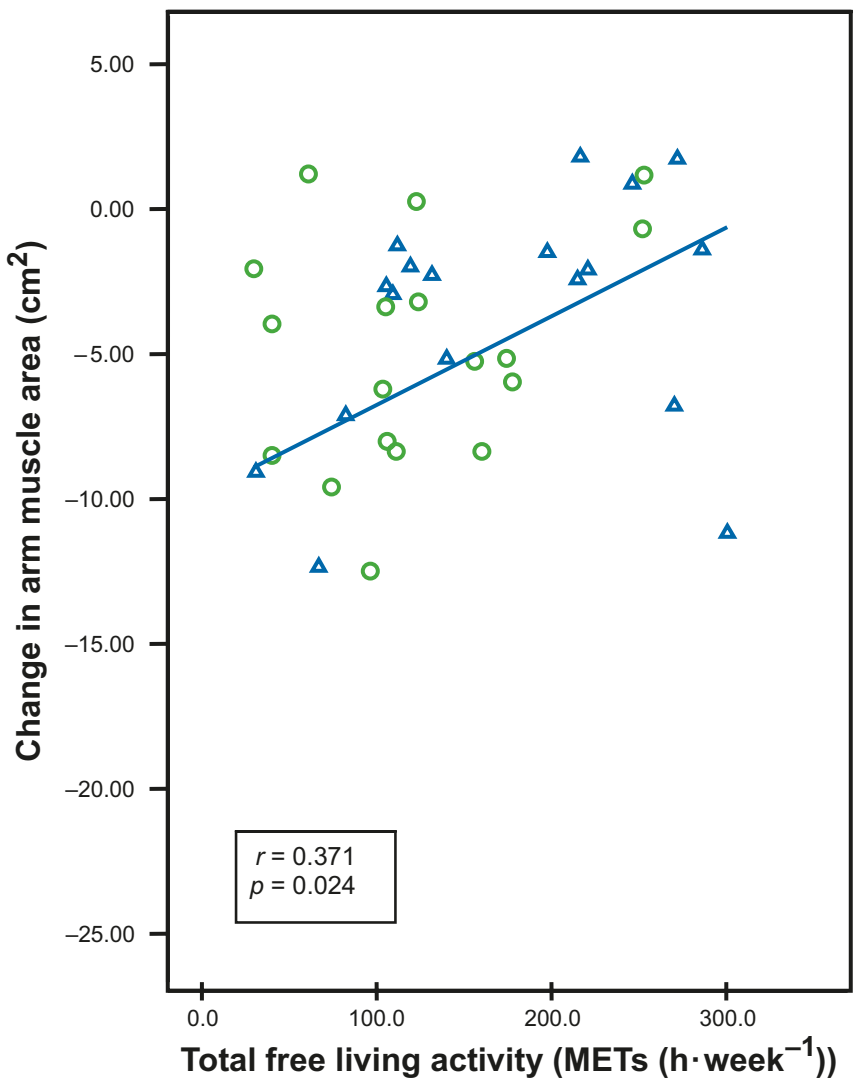

$\Delta$ Low carbohydrate-high-fat $\bigcirc$ High Carbohydrate-low-fat

and to reduce the energy density of the diet (Abete et al. 2006). Furthermore, low-fat diets are often more satiating because they usually contain high amounts of complex $\mathrm{CHO}$-protein, and some studies have shown that a reduction in fat intake can result in weight loss that is clinically significant (Saris et al. 2000). In contrast, other researchers have suggested that short-term weight loss is greater in obese women on a low-CHO-high-fat diet than in those on a lowfat diet, even when reported energy intake is similar, although some of these dietary patterns are still under debate (Martinez and Parra 2006; Lean and Lara 2004). Several mechanisms may explain these findings, such as a severe $\mathrm{CHO}$ restriction depleting glycogen stores, leading to excretion of bound water; the appetite-suppressing nature of ketogenic diets; the accompanying high protein content being highly satiating; or limited food choices, leading to spontaneously decreased energy intake (Astrup et al. 2004; Meckling and Sherfey 2007).

Interestingly, there was a negative association between the difference in the arm muscle area (final-baseline) after the intervention and the sedentary index. In addition, a positive association between the difference in the arm muscle area and total free-living activity was observed. Overall, these results indicate that less-active obese women lost more muscle 
Fig. 2. Interaction between the low-carbohydrate-high-fat vs. high-carbohydrate-low-fat distribution in the 2 energy-restricted diets followed during 10 weeks with activity at work (A) and the sedentary index (B). METs, metabolic equivalents.
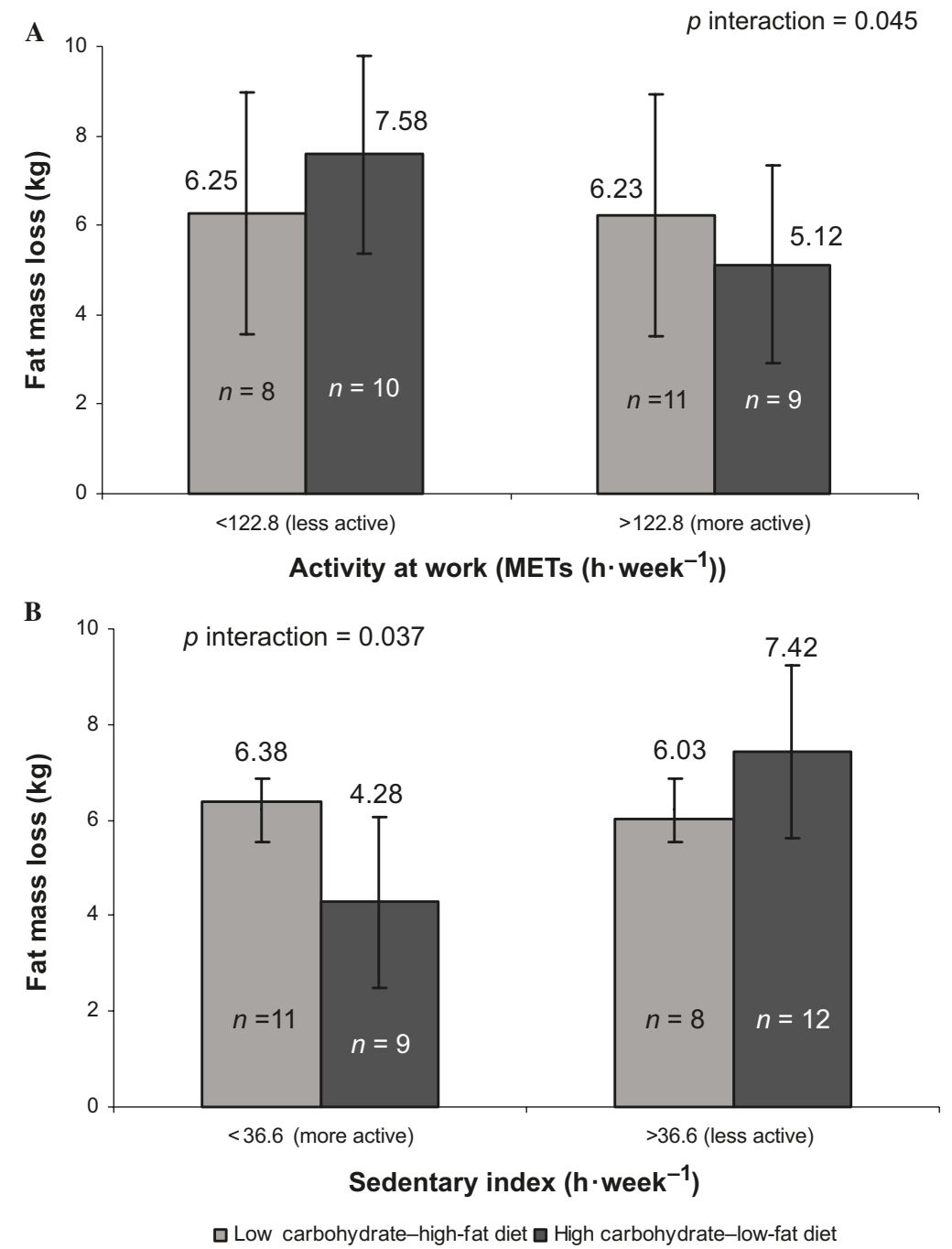

than active women after following a hypocaloric diet. The muscle depletion is likely produced by the reduced level of exercise, and it is the result of muscle protein loss, which usually accompanies inactivity. Indeed, total inactivity has been associated with a quick reduction in muscle strength in previous studies (Powers et al. 2005).

The most relevant findings of this study are: First, lessactive women who consumed a high-CHO-low-fat hypocaloric diet lost more fat mass than those who consumed a low-CHO-high-fat hypocaloric diet; second, those relatively more active participants with a low-CHO-high-fat energy-restricted diet lost more body fat mass than those who followed a high-CHO-low-fat hypocaloric diet. Inactive lifestyles and low physical fitness may produce a low muscle fat oxidation capacity, and the consumption of a high-fat diet by such individuals would facilitate fat storage (Smith et al. 2000; Stiegler and Cunliffe 2006). The contribution of fat oxidation can increase with more prolonged exercise at the cost of $\mathrm{CHO}$ oxidation (Wagenmakers et al. 1993). Our findings could be interpreted to indicate that relatively more active lifestyles can show an enhanced muscle capacity to oxidize lipids from moderate- to-high-fat diets, whereas the $\mathrm{CHO}$ coming from the highCHO-low-fat diet is a more readily available fuel source for physical activity, specifically in sedentary situations.

In this context, exercise increases fat oxidation by activating those enzymes necessary for triacylglycerol hydrolysis and transport (Spriet and Watt 2003). Furthermore, acute episodes of physical activity regulate the flux of $\mathrm{CHO}$ into the tricarboxylic acid cycle (Howlett et al. 1998). Other mechanisms potentially associated with fat loss could be a rise in nervous function, because aerobic exercise increases sympathetic activity, which is involved in fat oxidation (Brooks and Mercier 1994). In addition to this, it has been reported that high-CHO-low-fat diets may reduce fat oxidation and increase $\mathrm{CHO}$ oxidation during exercise, whereas high-fat diets may increase fat oxidation but do not lower glycogen utilization (Tsai et al. 2003). Thus, physical inactivity combined with a high-fat diet may be important in lipid deposition and obesity maintenance (Shepard et al. 2001). Interestingly, less-active individuals were more prone to lose muscle mass under an energy-restricted diet than more physically active subjects. These arguments confirm that the macronutrient distribution of an energy-restricted diet may 
interact with energy expenditure mediated by physical activity. Moreover, the fact that some of the conclusions of this trial are based on calculated measures for arm muscle area and fat-free mass or physical activity assignment, which were in agreement with expectations, but were made by indirect approaches, is a limitation of the study. It is also true that some women might have been in a perimenopausal status. In any case, it is clear that different dietary strategies for weight loss in obesity concerning macronutrient content should become a matter of further investigation (Stiegler and Cunliffe 2006). In this context, a protective effect of physical activity, independent of obesity, on metabolic risk factors has been reported ( $\mathrm{Li}$ et al. 2006). Indeed, combined diet and exercise may reverse certain metabolic syndrome features (Anderssen et al. 2007). However, studies concerning fuel utilization depending on the macronutrient distribution of the dietary intake as affected by habitual physical activity are scarce, and because exercise capacity is decreased in obesity, care should be taken when designing exercise programs for obese subjects (Hulens et al. 2001; Meckling and Sherfey 2007). Exercise should be an important part of any weight-loss program, but an adequate combination of exercise and CHO-fat intake is apparently required to prevent muscle atrophy and promote greater weight and fat loss.

This trial highlights that less-active obese individuals may benefit specifically from a high-CHO-low-fat diet to lose weight, whereas more-active obese individuals may have an advantage by consuming a low-CHO-high-fat diet.

\section{Acknowledgements}

This work has been partially supported by grants from the Navarra Government (Health Department), CIBERobn, and the Special Research Line of Nutrition, Obesity and Health of the University of Navarra (LE/97). Constanza Matilde Lopez-Fontana held a scholarship from the Friend's Association of the University of Navarra. None of the authors have any conflict of interest about financial or professional subject matters concerning the findings of this study. Thanks are given to M. Edwards from the University of Malaga (Spain) who carefully read this version of the manuscript for English language. Paul Miller from the Language Institute at the University of Navarra (Scientific Section) made the final check for English grammar and style, which is gratefully acknowledged. The subjects participated in the study after giving a written consent, which was approved by the Local Ethical Committee at the Navarra University Clinic.

\section{References}

Abete, I., Parra, M.D., and Zulet, M.A. 2006. Different dietary strategies for weight loss in obesity: role of energy or macronutrient content. Nutr. Res. Rev. 19: 5-17. doi:10.1079/NRR2006112. PMID:19079872.

Abete, I., Parra, D., and Martinez, J.A. 2008. Energy-restricted diets based on a distinct food selection affecting the glycemic index induce different weight loss and oxidative response. Clin. Nutr. 27: 545-551. doi:10.1016/j.clnu.2008.01.005. PMID: 18308431.

Ainsworth, B.E., Haskell, W.L., Whitt, M.C., Irwin, M.L., Swartz, A.M., Strath, S.J., et al. 2000. Compendium of physical activ- ities: an update of activity codes and MET intensities. Med. Sci. Sports Exerc. 32: S498-S504. doi:10.1097/00005768200009001-00009. PMID:10993420.

Anderssen, S.A., Carroll, S., Urdal, P., and Holme, I. 2007. Combined diet and exercise intervention reverses the metabolic syndrome in middle-aged males: results from the Oslo Diet and Exercise Study. Scand. J. Med. Sci. Sports, 17: 687-695. PMID:17331082.

Astrup, A., Meinert-Larsen, T., and Harper, D. 2004. Atkins and other low carbohydrate diets: hoax or an effective tool for weight loss? Lancet, 364: 897-899. doi:10.1016/S01406736(04)16986-9. PMID:15351198.

Bes-Rastrollo, M., Sanchez-Villegas, A., Gomez-Gracia, E., Martínez, J.A., Pajares, R.M., and Martínez-González, M.A. 2006. Predictors of weight gain in a Mediterranean cohort: the Seguimiento Universidad de Navarra Study. Am. J. Clin. Nutr. 83: 362-370. PMID:16469996.

Blaak, E.E., Hul, G., Verdich, C., Stich, V., Martinez, J.A., Petersen, M., et al. 2007. Impaired fat-induced thermogenesis: the NUGENOB Study. Obesity (Silver Spring), 15: 653-663. doi:10.1038/oby.2007.606. PMID:17372316.

Blundell, J.E., Cooling, J., and King, N.A. 2002. Differences in postprandial responses to fat and carbohydrate loads in habitual high and low fat consumers (phenotypes). Br. J. Nutr. 88: 125132. doi:10.1079/BJN2002609. PMID:12144716.

Brooks, G.A., and Mercier, J. 1994. Balance of carbohydrate and lipid utilization during exercise: the "crossover" concept. J. Appl. Physiol. 76: 2253-2261. PMID:7928844.

Ekelund, U., Särnblad, S., Brage, S., Ryberg, J., Wareham, N.J., and Aman, J. 2007. Does physical activity equally predict gain in fat mass among obese and non-obese young adults? Int. J. Obes. 31: 65-71. doi:10.1038/sj.ijo.0803361.

Ferrannini, E. 1988. The theoretical bases of indirect calorimetry: a review. Metabolism, 37: 287-301. doi:10.1016/0026-0495(88) 90110-2. PMID:3278194.

Ford, E.S., Mokdad, A.H., Giles, W.H., Galuska, D.A., and Serdula, M.K. 2005. Geographic variation in the prevalence of obesity, diabetes and obesity-related behaviors. Obes. Res. 13: 118-122. doi:10.1038/oby.2005.15. PMID:15761170.

Gibson, R.S. 2005. Principles of nutritional assessment. 2nd ed. Oxford University Press, New York, N.Y..

Howlett, R.A., Parolin, M.L., and Dyck, D.J. 1998. Regulation of skeletal muscle glycogen phosphorylase and PDH at varying exercise power outputs. Am. J. Physiol. 275: R418-R425. PMID: 9688676.

Hulens, M., Vansant, G., Lysens, R., Claessens, A.L., and Muls, E. 2001. Exercise capacity in lean versus obese women. Scand. J. Med. Sci. Sports, 11: 305-309. doi:10.1034/j.1600-0838.2001. 110509.x. PMID:11696216.

Janiszewski, P.M., and Ross, R. 2007. Physical activity in the treatment of obesity: beyond body weight reduction. Appl. Physiol. Nutr. Metab. 32: 512-522. doi:10.1139/H07-018. PMID: 17510691.

Karnehed, N., Tynelius, P., Heitmann, B.L., and Rasmussen, F. 2006. Physical activity, diet and gene-environment interactions in relation to body mass index and waist circumference: the Swedish young male twins study. Public Health Nutr. 9: 851858. doi:10.1017/PHN2005926. PMID:17010250.

Lean, M.E., and Lara, J. 2004. Is Atkins dead (again)? Nutr. Metab. Cardiovasc. Dis. 14: 61-65. doi:10.1016/S0939-4753(04) 80011-5. PMID:15242237.

Li, C.L., Liu, F.H., and Lin, J.D. 2006. Protective effect of physical activity independent of obesity on metabolic risk factors. Int. J. Sport Nutr. Exerc. Metab. 16: 255-269. PMID:16948482. 
Martinez, J.A., and Parra, M.D. 2006. Life-threatening complications of the Atkins diet. Lancet, 368: 23. doi:10.1016/S01406736(06)68953-8. PMID:16815366.

Martinez-Gonzalez, M.A., Martinez, J.A., Hu, F.B., Gibney, M.J., and Kearney, J. 1999. Physical inactivity, sedentary lifestyle and obesity in the European Union. Int. J. Obes. Relat. Metab. Disord. 23: 1-10. doi:10.1038/sj.ijo.0801049.

Martínez-Gonzalez, M.A., Lopez-Fontana, C., Varo, J.J., SánchezVillegas, A., and Martínez, J.A. 2005. Validation of the Spanish version of the physical activity questionnaire used in the Nurses' Health Study and the Health Professionals' Follow-up Study. Public Health Nutr. 8: 920-927. PMID:16277809..

Meckling, K.A., and Sherfey, R. 2007. A randomized trial of a hypocaloric high-protein diet, with and without exercise, on weight loss, fitness, and markers of the Metabolic Syndrome in overweight and obese women. Appl. Physiol. Nutr. Metab. 32: 743752. doi:10.1139/H07-059. PMID:17622289.

Powers, S.K., Kavazis, A.N., and DeRuisseau, K.C. 2005. Mechanisms of disuse muscle atrophy: role of oxidative stress. Am. J. Physiol. Regul. Integr. Comp. Physiol. 288: R337-R344. PMID: 15637170.

Prentice, A.M. 1998. Manipulation of dietary fat and energy density and subsequent effects on substrate flux and food intake. Am. J. Clin. Nutr. 67: 535S-541S. PMID:9497166..

Saris, W.H., Astrup, A., Prentice, A.M., Zunft, H.J., Formiguera, X., Verboeket-van de Venne, W.P., et al. 2000. Randomized controlled trial of changes in dietary carbohydrate/fat ratio and simple vs. complex carbohydrates on body weight and blood lipids: the CARMEN study. The Carbohydrate Ratio Management in European National diets. Int. J. Obes. Relat. Metab. Disord. 24: 1310-1318. doi:10.1038/sj.ijo.0801451. PMID:11093293.

Schrauwen, P. 2007. Physical activity and diabetes: current considerations. Appl. Physiol. Nutr. Metab. 32: 535-536. doi:10.1139/ H07-033. PMID: 17510693.

Schrauwen, P., and Westerterp, K.R. 2000. The role of high-fat diets and physical activity in the regulation of body weight. Br. J. Nutr. 84: 417-427. PMID:11103212.

Shai, I., Schwarzfuchs, D., Henkin, Y., Shahar, D.R., Witkow, S., Greenberg, I., et al.; Dietary Intervention Randomized Controlled Trial (DIRECT) Group. 2008. Weight loss with a lowcarbohydrate, Mediterranean, or low-fat diet. N. Engl. J. Med. 359: 229-241. doi:10.1056/NEJMoa0708681. PMID:18635428.

Shepard, T.Y., Weil, K.M., Sharp, T.A., Grunwald, G.K., Bell, M.L., Hill, J.O., et al. 2001. Occasional physical inactivity combined with a high-fat diet may be important in the development and maintenance of obesity in human subjects. Am. J. Clin. Nutr. 73: 703-708. PMID:11273843.

Smith, S.R., De-Jonge, L., Zachwieja, J.J., Roy, H., Nguyen, T., Rood, J., et al. 2000. Concurrent physical activity increases fat oxidation during the shift to a high fat diet. Am. J. Clin. Nutr. 72: 131-138. PMID:10871571.

Spriet, L.L., and Watt, M.J. 2003. Regulatory mechanisms in the interaction between carbohydrate and lipid oxidation during exercise. Acta Physiol. Scand. 178: 443-452. doi:10.1046/j.1365201X.2003.01152.x. PMID:12864750.

Stiegler, P., and Cunliffe, A. 2006. The role of diet and exercise for the maintenance of fat-free mass and resting metabolic rate during weight loss. Sports Med. 36: 239-262. doi:10.2165/ 00007256-200636030-00005. PMID:16526835.

Tsai, A.C., Sandretto, A., and Chung, Y.C. 2003. Dieting is more effective in reducing weight but exercise is more effective in reducing fat during the earlyphase of a weight-reducing program in healthy humans. J. Nutr. Biochem. 14: 541-549. doi:10.1016/ S0955-2863(03)00105-0. PMID:14505816.

Wagenmakers, A.J.M., Brouns, F., Saris, W.H.M., and Halliday, D. 1993. Oxidation rates of orally ingested carbohydrates during prolonged exercise in men. J. Appl. Physiol. 75: 2774-2780. PMID:8125902.

World Health Organization. 1998. Obesity. Preventing and managing the global epidemic. Report No. 794. WHO, Geneva. 